\title{
Impact of Terminal Heat Stress on Pollen Viability and Yield Attributes of Rice (Oryza sativa L.)
}

\author{
N. Kumar, Nitin Kumar, A. Shukla, S.C. Shankhdhar and D. ShankhdhaR* \\ Department of Plant Physiology, College of Basic Sciences and Humanities, G. B. Pant University of \\ Agriculture and Technology, Pantnagar - 263145 (U. S. Nagar) Uttarakhand, India
}

(Received 12 June 2014; Accepted 24 February 2015; Communicated by H. Grausgruber)

\begin{abstract}
Global warming is rising as a serious concern affecting agricultural production worldwide. Rice is a staple food crop and the threshold temperature for its pollination is $35^{\circ} \mathrm{C}$. A rise in temperature above this value can cause pollen sterility and may severely affect fertilization. Therefore, a study emphasizing the rise in temperature with respect to pollen viability was conducted with eleven rice genotypes during kharif seasons of 2010 and 2011 in indigenous field conditions. Increasing mean temperature by $12{ }^{\circ} \mathrm{C}$ at full flowering was found to severely affect the spikelet attributes of the crop. All genotypes showed spikelet sterility above $90 \%$ during both seasons. The study indicated that increased temperature may limit rice yield by affecting spikelet fertility and grain filling. The net reduction in grain yield was $30.4 \%$ and $27.6 \%$ in 2010 and 2011, respectively. A clear reduction in pollen size under high temperature was shown by scanning electron microscopy.
\end{abstract}

Keywords: high temperature, Oryza sativa, pollen viability, grain yield, yield loss

\section{Introduction}

Global warming is a serious threat worldwide, reducing world's agricultural production up to $16 \%$ by 2020 (Cline 2007). Prices of agricultural commodities are predicted to increase by $40 \%$ with a global temperature increase of $3{ }^{\circ} \mathrm{C}$ (Easterling et al. 2007). Climatic models predict an increase in mean air temperature of $2.0^{\circ} \mathrm{C}$ to $4.5^{\circ} \mathrm{C}$ with an increased variability around this mean (IPCC 2007). Rice (Oryza sativa L.) is one of the major staple food crops in terms of production, acreage and consumption. As world population increases rapidly, the demand for rice will grow to an estimated 2000 million metric tons by 2030 (Cho and Oki 2012). Rice production has been intensified in rainfedlowland and dryland (upland) cropping systems, many of which are prone to drought and high temperature (Coffman 1977). Previous studies have shown that spikelets are sterile and set no seed if they are exposed to temperatures $>35^{\circ} \mathrm{C}$ for about 5 days at flowering (Satake and Yoshida 1978). Temperature fluctuations occurring during flowering can induce morphological changes in flower organs. These changes are dependent on the intensity, duration and rate of temperature increase. In rice, flowering (anthesis and fertiliza-

\footnotetext{
*Corresponding author; E-mail: dshankhdhar@rediffmail.com; Phone: +919412541095
} 
tion), and to a lesser extent booting (microsporogenesis), are the most susceptible development stages to temperature (Farrell et al. 2006). Temperatures above the temperature threshold increased the number of spikelets with inviable pollen, while more than $75 \%$ pollen viability was observed in untreated plants (Endo et al. 2009). The development of the male reproductive organ is highly sensitive to variation in temperatures at anthesis leading to high sterility, impaired fertility and grain filling (Liu et al. 2013). Saragih et al. (2013) reported that environmental stresses are the major cause of declining pollen production of rice and major crop plants. To understand how pollen viability of rice responds to high temperatures during the reproductive stage without disturbing the rhizospheric conditions, we have assessed the effects of terminal heat stress on pollen sterility, fertility and finally grain yield of different rice genotypes under field conditions.

\section{Materials and Methods}

\section{Experimental site}

The field experiments were conducted in kharif seasons (June-November) of 2010 and 2011 at the Norman E. Borlaug Crop Research Centre, G. B. Pant University of Agriculture and Technology Pantnagar, U.S. Nagar (Uttrakhand), India. The experimental site lies in the Tarai plains, about $30 \mathrm{~km}$ south of the foothills of Shivalik range of the Himalayas $\left(29^{\circ} \mathrm{N}, 79^{\circ} 29^{\prime} \mathrm{E}, 244 \mathrm{~m}\right.$ a.s.1.). The soil is classified as typic hapludoll with a loam texture, $\mathrm{pH} 7.0,0.278 \mathrm{dSm}^{-1}$ E.C. at $25^{\circ} \mathrm{C}, 10.3 \mathrm{~g}$ organic $\mathrm{C} \mathrm{kg}^{-1}$.

\section{Plant materials and treatments}

The investigated rice genotypes were experimental inbred lines (i.e. IET 21404, IET 21405, IET 21411, IET 21415, IET 21577 and IET 21582) and hybrids (i.e. KRH-2, PA 6129, PA 6201, PA 6444 and PHB 71) obtained from the Directorate of Rice Research, Rajendranagar, Hyderabad. Each genotype was grown with three replications in a randomized block design. Plot size was $1 \mathrm{~m}^{2}$. Heat stress was applied from anthesis to maturity (about 60 days).Terminal heat stress was imposed in one block by covering with 0.1 $\mathrm{mm}$ thick UV transparent PVC film. A poly-house was made under field condition during the reproductive stage. Poly-house was made by bamboo sticks with an open air inlet at one end and outlet at another end with north south direction for sufficient ventilation and maximum exposure to sunlight. The height of the poly-house was about $2 \mathrm{~m}$ for proper aeration and plant growth. Another block, which was not covered, was used as control. Maximum and minimum temperature was recorded daily with the help of an automatic thermometer inside and outside the PVC tunnel. The mean temperature inside the tunnel varied about $12{ }^{\circ} \mathrm{C}$ during the period of full flowering (Table S1*). Filled and chaffy grains were counted with the sodium chloride density gradient method at 1.20 and 1.06 specific gravity. At 1.20 specific gravity, randomly chosen panicles from treated and con-

*Further details about the Electronic Supplementary Material (ESM) can be found at the end of the article. 
trol plants were collected and transferred in $\mathrm{NaCl}$ solution $(315 \mathrm{~g} \mathrm{NaCl}$ in $1 \mathrm{~L}$ distilled water). After stirring the sunken, high density grains were counted. Floated chaffy grains were transferred to the 1.06 specific gravity $\mathrm{NaCl}$ solution $(90 \mathrm{~g} \mathrm{NaCl}$ in $1 \mathrm{~L}$ distilled water) and the process of counting was repeated. Sunken grains were classified as density grains, whereas the remaining floating spikelets were chaffy.

Rice florets were sampled just before anthesis. Florets were opened by removing the lemma with the help of a needle and pollen grains were dusted from the anthers onto a microscope slide with a brush. Pollen grains were stained with $10 \%$ iodine solution and observed under light microscope. Only fertile pollen grains were stained with iodine, while pollen grains which did not get stained were sterile. At maturity, a net plot of $1 \mathrm{~m}^{2}$ was harvested for recording biomass and grain yield. After sun drying in the field, the total above ground biomass yield $\left(\mathrm{kg} \mathrm{m}^{-2}\right)$ and, after threshing, the grain yields $\left(\mathrm{g} \mathrm{m}^{-2}\right)$ were determined.

\section{Characterization of pollen morphology using scanning electron microscopy}

Scanning electron microscopy (SEM) was done for visualizing pollen grains of a heat sensitive genotype IET 21405 under control and heat treated conditions to see the clear cut differences in pollens. Based on the physiological and biochemical observations in eleven genotypes during two consecutive years IET 21405 was selected as heat sensitive for this purpose microscope stubs were prepared by dusting pollen from open flowers on double-sided carbon tape affixed to the stub. Samples were allowed to dry overnight. Then they were coated with approximately $100 \AA$ gold in a vacuum sputter instrument. Specimens were observed by using a JEOL JSM-6610LV scanning electron microscope under high vacuum at $5.00 \mathrm{KV}$.

\section{Statistical analysis}

Data of all parameters was analyzed by ANOVA (Analysis of variance) in accordance to the two factorial RCBD (randomized complete block design) using SPSS-16 software. Means were tested using Duncan's test at a significance level of 5\%.

\section{Results}

\section{Weather}

Maximum and minimum temperatures in both vegetation periods are presented in Table $\mathrm{S} 1$. The data indicated that in both years the differences in maximum temperature between the PVC tunnel and the control was greater than the differences in minimum temperatures. 


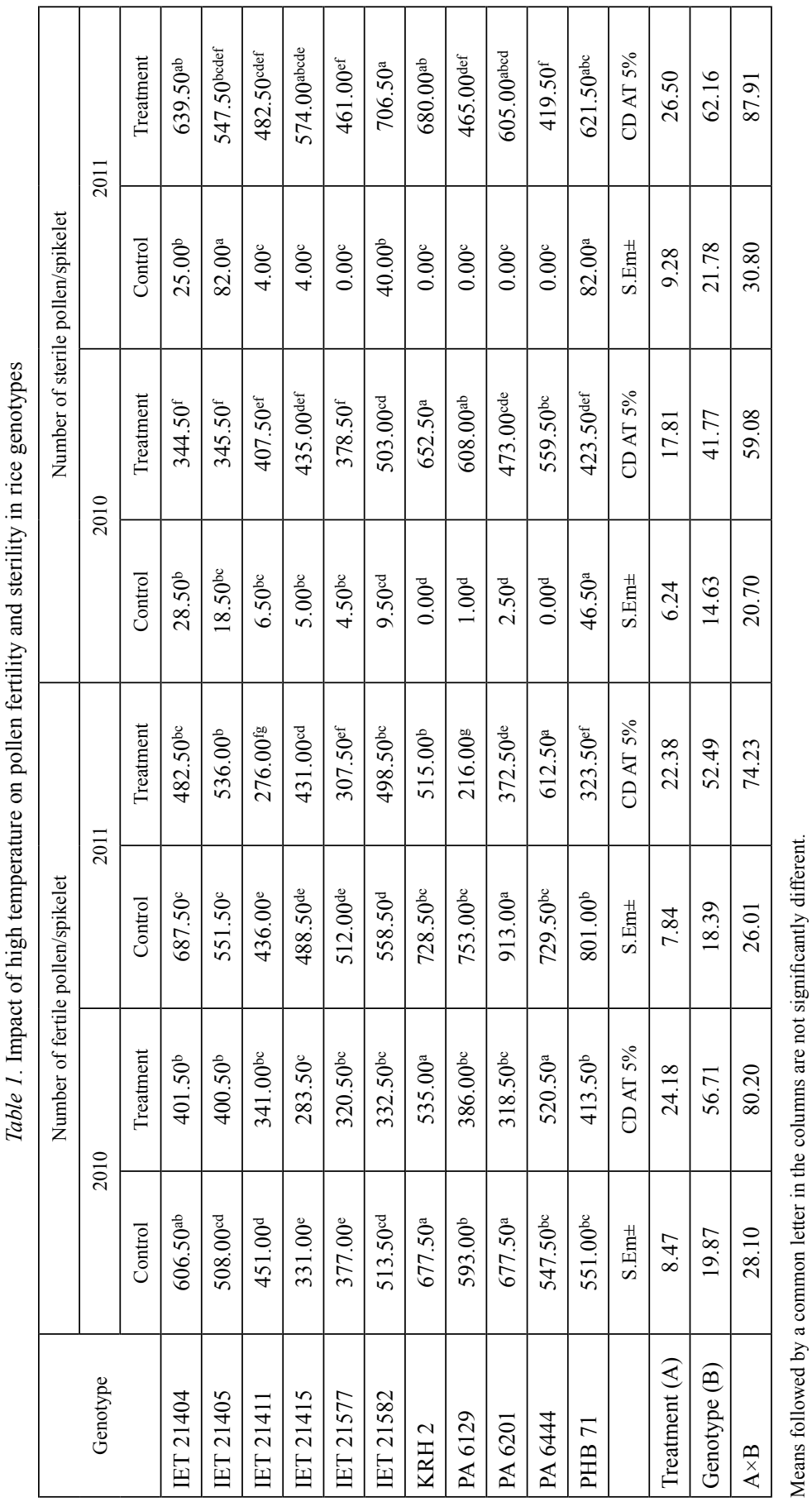




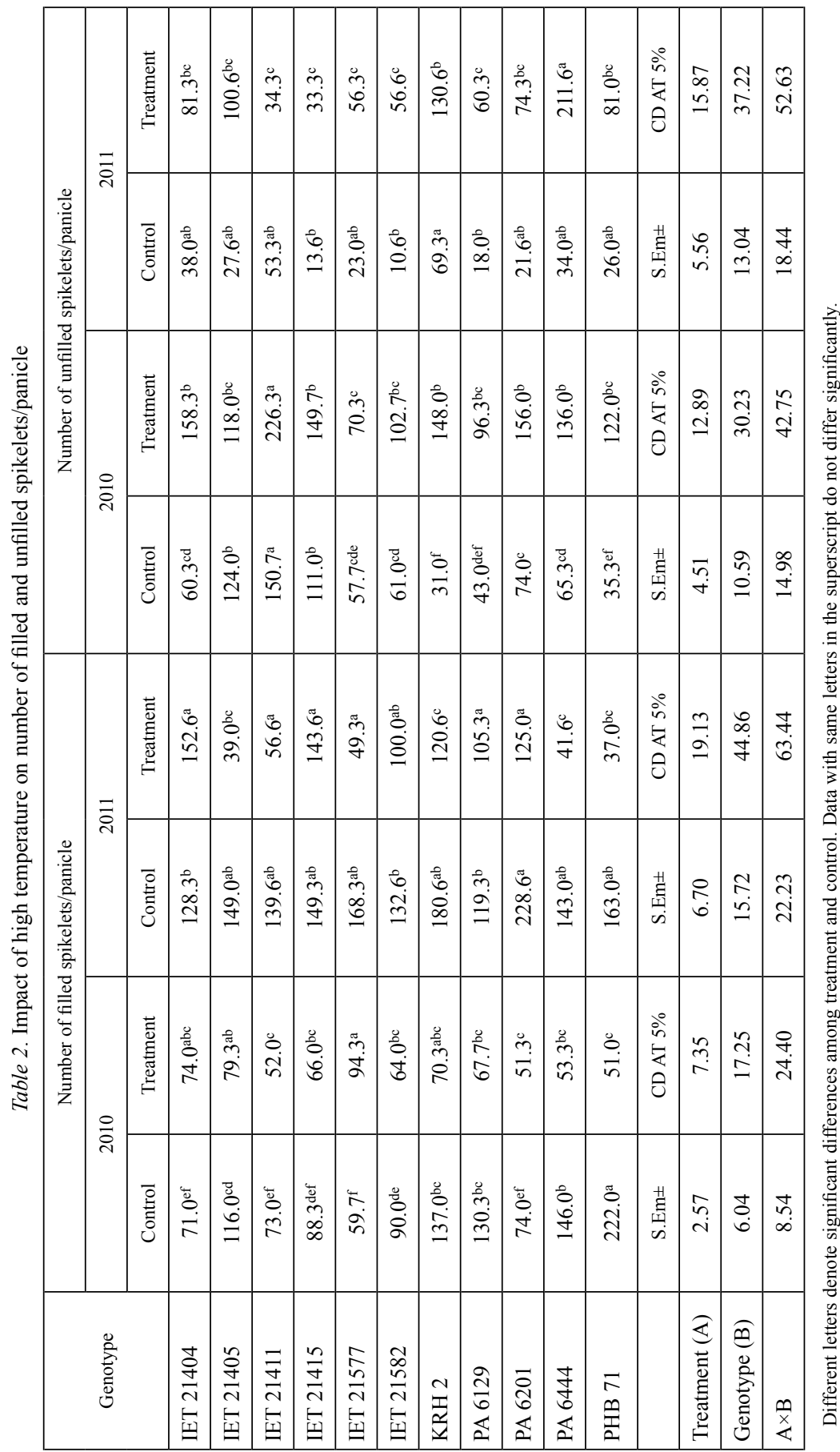




\section{Pollen fertility and sterility}

Temperatures $<30{ }^{\circ} \mathrm{C}$ during the reproductive stage were advantageous with respect to pollen viability, whereas temperatures $>30^{\circ} \mathrm{C}$ were problematic. Pollen viability was expressed as percentage of stained round shaped pollen grains (PP1). The data clearly indicate that the reproductive stage of rice is highly sensitive to high temperature. In 2010 pollen fertility was reduced by $<15 \%$ in genotypes IET 21415 , IET 21577 and PA 6444 , $15-30 \%$ in IET 21405, IET 21411, KRH 2 and PHB 71, and 30-50\% in IET 21404, IET 21583, PA 6129 and PA 6201. In 2011 a reduction of pollen fertility $<15 \%$ was observed
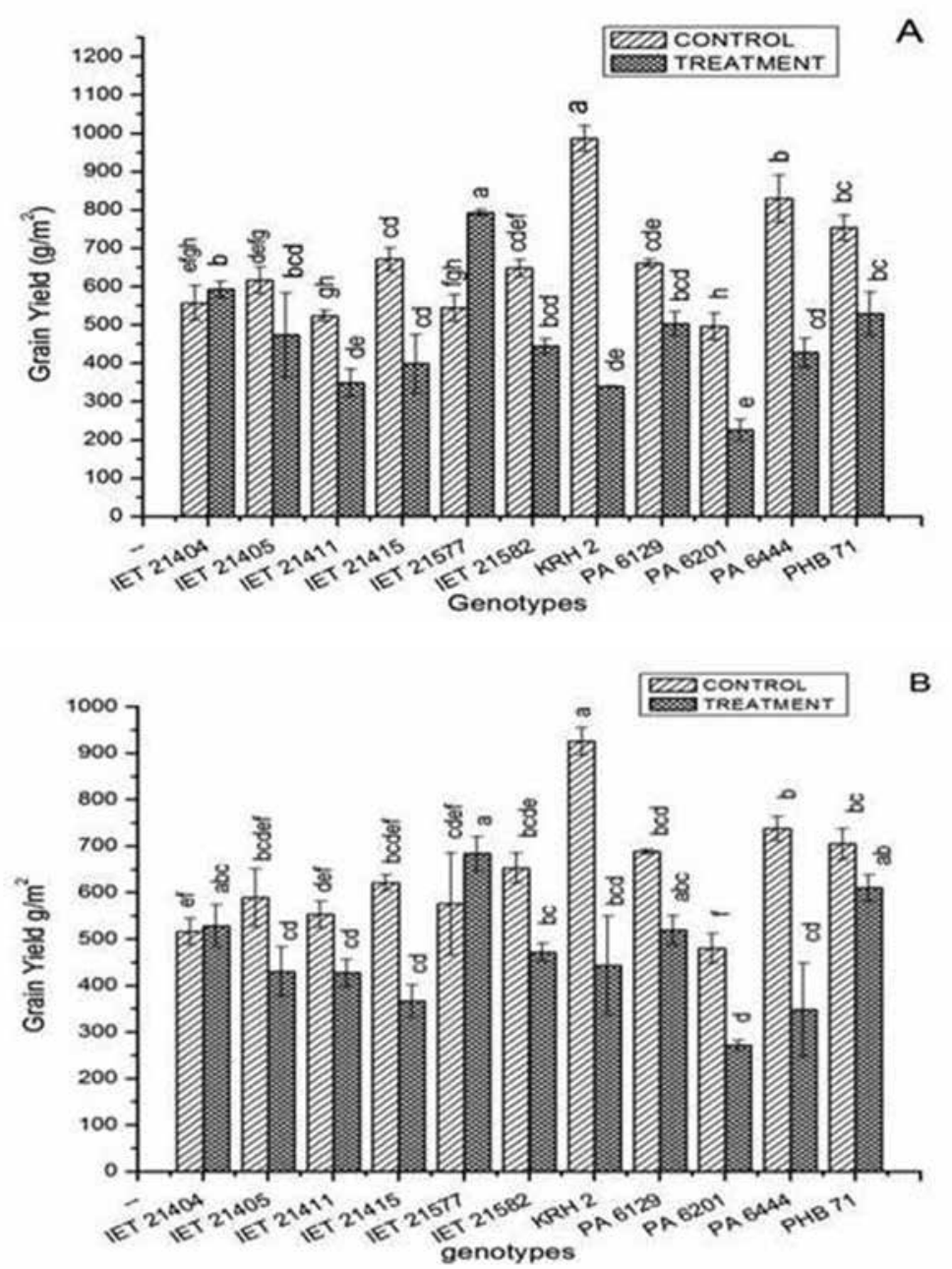

Figure 1. Effect of heat stress treatment on grain yield $\left(\mathrm{g} / \mathrm{m}^{2}\right)$ in eleven genotypes of rice in the planting season 2010 (A) and 2011 (B). Vertical bars indicate \pm standard error. Bars superscripted by a different letter in the same genotype are significantly different at $P<0.05$ 
for IET 21405, IET 21577 and IET 21415, 15-30\% reduction for IET 21404, IET 21582 and PA6444, 30-50\% reduction for IET 21411 and KRH 2, and $>50 \%$ reduction for PA 6129, PA 6201 and PHB 71 (Table 1). Morphological observations revealed that pollen sterility in plants exposed to high temperatures was higher than that in control plants. In 2010 number of sterile pollen varied from 344.5 in IET21404 to 652.5 in KRH-2 at high temperature stress whereas in control maximum 46.5 was observed in PHB-71. In 2011 the number of sterile pollen was minimum 419.5 in PA6444 and maximum 706.5 in case of IET 21582.

\section{Number of filled grains and unfilled spikelets/panicle}

Number of filled grains of randomly chosen panicles was higher in the heat treatment than in control for IET 21404 and IET 21577 in 2010. In 2011 this trend was confirmed for IET 21404, while all other genotypes showed a lower number of filled grains in the heat treatment. The percent reduction under heat treatment of filled grains as compared to control varied from 16-66\% in 2010 and $11-64 \%$ in 2011 . However, in IET $2157712.66 \%$ increment was observed in 2010 (Table S2). Similarly, the number of unfilled spikelets increased in most of the genotypes when the plants were heat treated (Table 2).

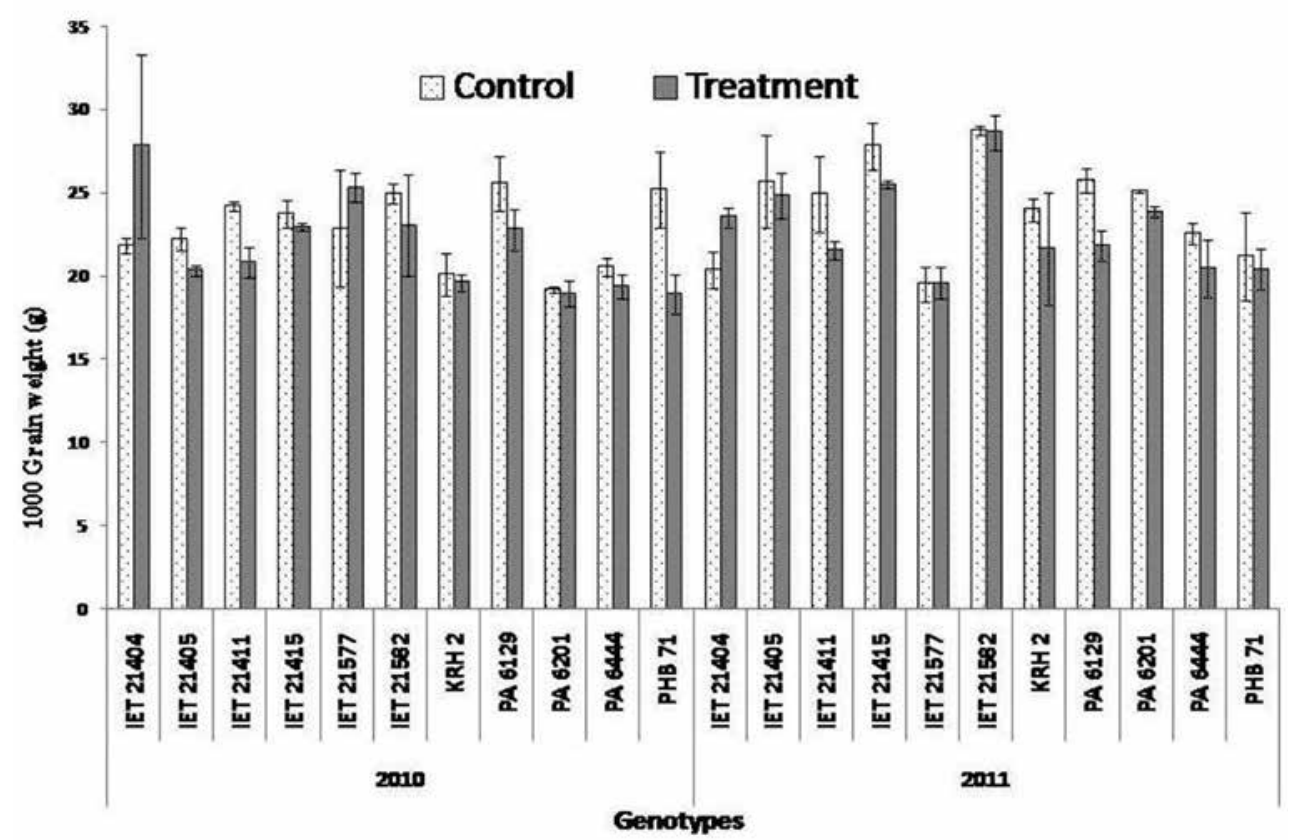

Figure 2. Effect of heat stress treatment on 1000 grain weight in eleven genotypes of rice in the planting season 2010 and 2011. Vertical bars indicate \pm standard error 


\section{Yield}

For IET 21404 and IET 21577 higher grain yield and 1000 grain weight was observed in the heat treatment in both seasons. Hybrids showed a yield loss of $>30 \%$, whereas yield loss of inbred lines was $>15 \%$ compared to the control (Fig. 1). More or less similar trend was found in 1000 grain weight i.e. $>12 \%$ and $>13 \%$ reduction in inbred lines and hybrids respectively (Fig. 2).

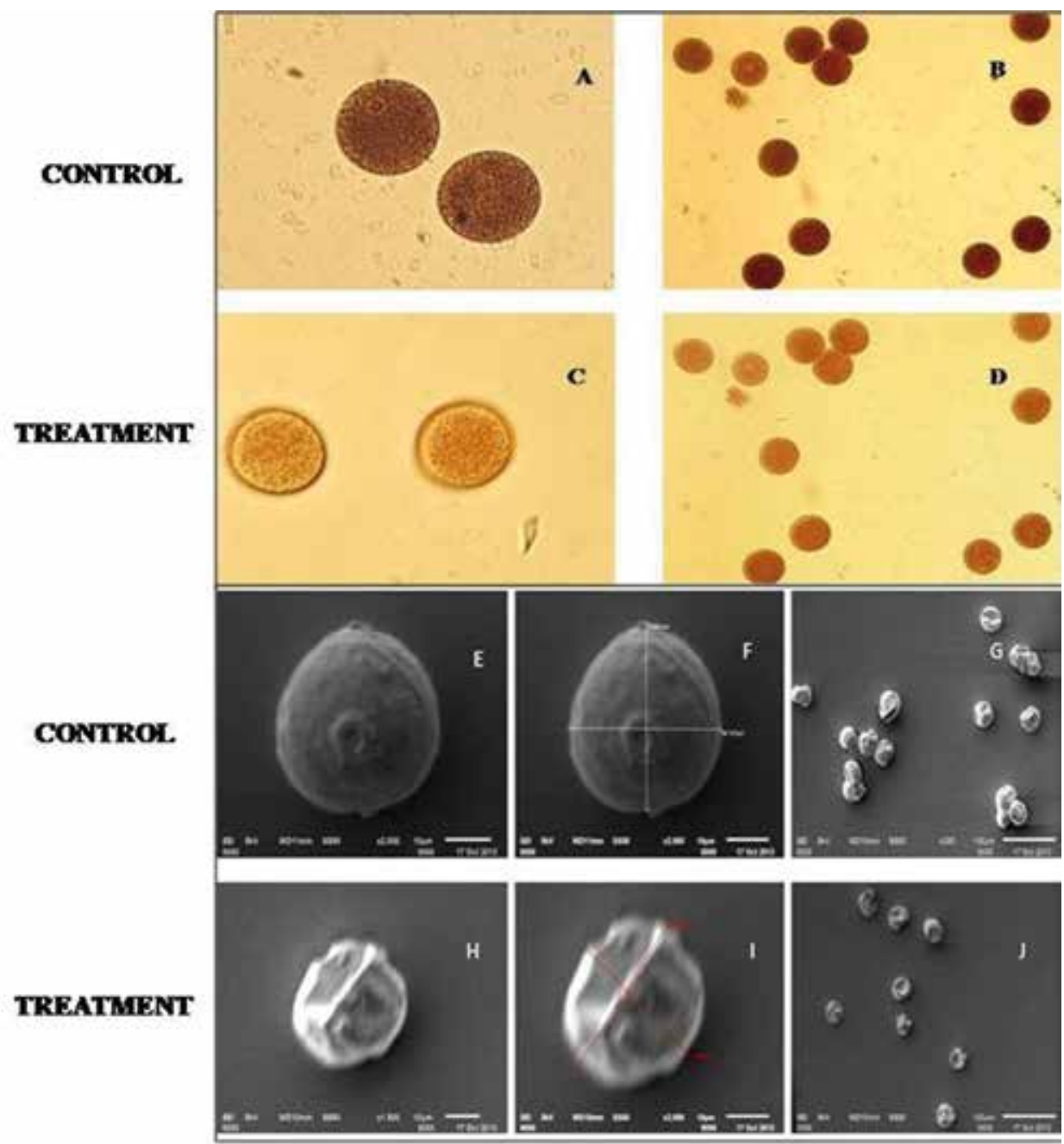

Figure 3. Studies of rice pollen grains under light and Scanning electron microscope under light microscope (A and $\mathrm{B}$ ) shows viable pollen, $(\mathrm{C}$ and $\mathrm{D})$ shows non viable pollen and Scanning electron microscope images in control $(\mathrm{E}, \mathrm{F}$ and $\mathrm{G})$ and in treatment $(\mathrm{H}, \mathrm{I}$ and $\mathrm{J})$ 


\section{Scanning electron microscopic analysis of pollen}

In SEM study pollen grains in untreated plants displayed normal round shape having a diameter of $36.1 \mu \mathrm{m}$, whereas in treated plants the pollen grains were smaller (diameter: $31.4 \mu \mathrm{m}$ ). Under normal conditions mature rice pollen has a single operculate aperture. The normal pollen grains had a smooth surface with areolate sculpture. There were some small spinules on isolated islets. Therefore, temperatures $>30^{\circ} \mathrm{C}$ decrease the ability of pollen grain to swell and reduce the size and diameter of pollen grain up to $4.7 \mu \mathrm{m}$ (Fig. 3).

\section{Discussion}

This study revealed a broad genotypic variation for number of fertile and sterile pollen per spikelet, number of filled and unfilled spikelets per panicle and yield. Heat stress decreased spikelet fertility in both seasons. This reduction in spikelet fertility was probably due to high temperatures at full flowering. Lower pollen production at elevated temperature may be attributed to impaired cell division of microspore mother cells (Takeoka et al. 1992). High temperatures resulted also in a loss of pollen viability due to poor pollen germination and retarded pollen tube growth besides poor anther dehiscence. This finding is supported with the study of Mohammed and Tarpley (2009) reporting reduced spikelet fertility in rice caused by high temperatures during booting. High temperature stress adversely affected plant growth, development, physiological processes, and finally yield (Hasanuzzaman et al. 2013). Similarly, we observed a significant reduction in spikelet fertility. High temperature induces male sterility and associated with several morphological alterations of the sporophytic anther tissues such as tapetum, epidermis, endothecium and stomium. These alterations of tissue were found in tomato after exposure to 3 days at $36{ }^{\circ} \mathrm{C} / 26^{\circ} \mathrm{C}$ (day/night). Most of the alterations due to high temperature occur in the tapetum layer. Because the tapetum secretes callase to release the microspores from the tetrad wall and acts as a nutritive source during microspore development (Scott et al. 2004; Ma et al. 2005; Sakata and Higashitani, 2008). High temperature stress induced anther dehiscence, resulting in a reduced number of germinated pollen on the stigma and consequently reduced fertilization (Rang et al. 2011). Pollen production and viability is directly proportional to the grain yield. Exposure of pollen to high temperature at anthesis led to decreased pollen production and pollen shed. Possible reasons were inhibition of swelling of pollen grains, indehiscence of anthers and poor release of pollen grains, resulting in a low number of germinating pollen grains on the stigma. Genotypes with large anthers are more tolerant to high temperature because they higher number of pollen grains per anther compensates for the reduced number of pollen grains (Prasad et al. 2006; Shah et al. 2011). Moreover, high temperature during grain-filling caused spikelet sterility by shortening of the duration of grain-filling. In the present study grain filling of most genotypes except IET 21404 and IET 21577 was affected by elevated temperature. This might be due to unavailable supply with assimilates and the capacity of remobilizing carbohydrate reserves from vegetative organs to the grains under the stress (Li et al. 2013). Grain 
filling is also affected by impaired deposition of starch and protein under high temperature stress (Yamakawa and Hakata 2010). The results confirmed that high temperature reduces pollen fertility, leading to reduction in the number of pollen scattered on the stigma, thereby affecting fertility and fertilization of the pollen and ultimately grain yield markedly declined (Boden et al. 2013). Based on the results the genotypes were grouped into (i) sensitive (IET 21405, IET 21411, PA6129, PHB 71), (ii) moderately tolerant (IET 21415, KRH 2, PA6201, PA6444) and (iii) tolerant (IET 21404, IET 21577) to high temperature.

In rice, anthesis is one of the most sensitive stages to heat stress. High temperature stress during anthesis increased pollen sterility and finally caused losses in grain yield. In comparison to inbreds hybrids are more sensitive to high temperature stress. Reduction in grain yield was $8.6-54.5 \%$ in 2010 and $15.6-43.4 \%$ in 2011 . The highest grain yield was observed in both years for IET 21577. This variety can be considered as high yielding heat tolerant. With respect to heat stress IET 21404 showed the least reduction and, thus, can be considered a heat tolerant variety. Scanning electron microscopy showed a clear difference in pollen size between control and heat treated plants. The present findings may be useful for breeding rice crops resistant to thermal stress. With respect to global warming the identification of heat tolerant rice genotypes with minimized yield losses is of utmost importance for countries relying on rice as main staple crop.

\section{Acknowledgements}

The authors are thankful to the Directorate of Rice Research, Hyderabad and the Indian Council of Agricultural Research, New Delhi, for financial support under the All India Coordinated Rice Improvement Programme. We also thankful to the Department of Biological Sciences, College of Basic Sciences \& Humanities, and the Department of Veterinary Anatomy, College of Veterinary and Animal Sciences, Pantnagar, for providing their microscope facilities.

\section{References}

Boden, S.A., Kavanová, M., Finnegan, E.J., Wigge, P.A. 2013. Thermal stress effects on grain yield in Brachypodium distachyon occur via H2A. Z -nucleosomes. Genome Biol.14:R65.

Cho, J., Oki, T. 2012. Application of temperature, water stress, $\mathrm{CO}_{2}$ in rice growth models. Rice 5:10.

Cline, W.R. 2007. Global Warming and Agriculture: Impact Estimates by Country. Peterson Institute. Washington D.C., USA.

Coffman, W.R. 1977. Rice varietal development for cropping systems at IRRI. Proc. of Symp. on Cropping Systems Research and Development for the Asian Rice Farmer. IRRI. Los Baños, Philippines. pp. 359-371.

Easterling, W.E., Aggarwal, P.K., Batima, P., Brander, K.M.,Erda, L., Howden, S.M. 2007. Food, fibre and forest products. In: Parry, M.L., Canziani, O.F., Palutikof, J.P., van der Linden, P.J., Hanson, C.E. (eds), Climate change 2007: Impacts, adaptation and vulnerability. Contribution of working group II to the fourth assessment report of the IPCC. Cambridge University Press. Cambridge, UK. pp. 273-313.

Endo, M., Tsuchiya, T., Hamada, K., Kawamura, S., Yano, K., Ohshima, M., Higashitani, A., Watanabe, M., Kobayashi, M.K. 2009. High temperatures cause male sterility in rice plants with transcriptional alterations during pollen development. Plant and Cell Physiol. 50:1911-1922. 
Farrell, T.C., Fox, K.M., Williams, R.L., Fukai, S. 2006. Genotypic variation for cold tolerance during reproductive development in rice: screening with cold air and cold water. Field Crops Res. 98:178-194.

Hasanuzzaman, M., Nahar, K., Alam, M.M., Roychowdhury, R., Fujita, M. 2013. Physiological, biochemical, and molecular mechanisms of heat stress tolerance in plants. Int. J. of Mol. Sci. 14:9643-9684.

IPCC 2007. Intergovernmental Panel on Climate Change. Fourth Assessment Report of the Intergovernmental Panel on Climate Change: The Impacts, Adaptation and Vulnerability. Cambridge University Press. UK and New York, NY, USA.

Li, H., Cai1, J., Jiang, D., Liu, F., Dai T., Cao, W. 2013. Carbohydrates accumulation and remobilization in wheat plants as influenced by combined waterlogging and shading stress during grain filling. J. of Agron. and Crop Sci. 199: 38-48.

Liu, Q., Wu, X., Ma, J., Li, T., Zhou X., Guo, T. 2013. Effects of high air temperature on rice grain quality and yield under field condition. Agron. J. 105:446-454.

Ma, H. 2005. Molecular genetic analyses of microsporogenesis and microgametogenesis in flowering plants. Annu. Rev. Plant Biol. 56:393-434.

Mohammed, A.R., Tarpley, L. 2009. High nighttime temperatures affect rice productivity through altered pollen germination and spikelet fertility. Agric. and Forest Meteorology 149:999-1008.

Prasad, P.V.V., Boote, K.J., Allen, L.H., Sheehy, J.E., Thomas, J.M.G. 2006. Species, ecotype and cultivar differences in spikelet fertility and harvest index of rice in response to high temperature stress. Field Crops Res. 95:398-411.

Rang, Z.W., Jagadish, S.V.K., Zhou, Q.M., Craufurd P.Q., Heuer, S. 2011. Effect of high temperature and water stress on pollen germination and spikelet fertility in rice. Environ. and Exp. Bot. 70:58-65.

Sakata, T., Higashitani, A. 2008. Male sterility accompanied with abnormal anther development in plants, genes and environmental stresses with special reference to high temperature injury. Int. J. of Plant Developmental Biol. 2:42-51.

Saragih, A.A., Puteh, A.B., Ismail, M.R., Mondal, M.M. A. 2013. Pollen quality traits of cultivated (Oryza sativa L. ssp. indica) and weedy (Oryza sativa var. nivara) rice to water stress at reproductive stage. Aust. J. of Crop Sci. 7:1106-1112.

Satake, T., Yoshida, S. 1978. High temperature induced sterility in indica rice at flowering. Japanese J. of Crop Sci. 47:6-17.

Scott, R.J., Spielman, M., Dickinson, H.G. 2004. Stamen structure and function. Plant Cell 16:46-60.

Shah, F., Huang, J., Cui, K., Nie, L., Shah, T., Chen, C., Wang, K. 2011. Impact of high-temperature stress on rice plant and its traits related to tolerance. J. of Agric. Sci. 149:545-556.

Takeoka, Y., Al Mamun, A., Wada T., Kaufman, P.B. 1992. Primary features of the effect of environmental stress on rice spikelet morphogenesis. In: Reproductive adaptation of rice to environmental stress. Developments in Crop Science. Elsevier Science Publishers. Amsterdam, The Netherlands 22:113-141.

Yamakawa, H., Hakata, M. 2010. Atlas of rice grain filling-related metabolism under high temperature: joint analysis of metabolome and transcriptome demonstrated inhibition of starch accumulation and induction of amino acid accumulation. Plant Cell Physiol. 51:795-809.

\section{Electronic Supplementary Material (ESM)}

Electronic Supplementary Material (ESM) associated with this article can be found at the website of CRC at http://www.akademiai.com/content/120427/

Electronic Supplementary Table S1. Temperature recorded in two successive years

Electronic Supplementary Table S2. Impact of high temperature on number of filled grains/panicle 